\title{
Contribution to Paris Agreement of United Nation by Coil-EEFL lamps with Zero Electric Power Consumption
}

\author{
Lyuji Ozawa \\ Independent Scholar, Beijing, China
}

Email address:

rotsun4@hotmail.com

To cite this article:

Lyuji Ozawa. Contribution to Paris Agreement of United Nation by Coil-EEFL lamps with Zero Electric Power Consumption. International Journal of Materials Science and Applications. Vol. 6, No. 2, 2017, pp. 65-76. doi: 10.11648/j.ijmsa.20170602.11

Received: January 6, 2017; Accepted: January 16, 2017; Published: January 23, 2017

\begin{abstract}
Illumination by incandescent lamps is an essential necessity for our life activity. The operation of the lamps consumes about $30 \%$ of total electric power on the world. The reduction of the electric power consumption of the incandescent lamps is an urgent subject for the UN project. The developed coil-EEFL lamps miraculously have zero electric power consumption, without the scarification of the high illuminance $\left(\mathrm{lm}, \mathrm{m}^{-2}\right)$. The developed coil-EEFL lamps may respond on the requirement of the Paris Agreement and COP 16 of the UN project.
\end{abstract}

Keywords: Green Energy, FL Lamps, Power Consumption, Phosphor Screen, Superconductive Vacuum

\section{Introduction}

Our life activity extends to the dark rooms in houses, offices in buildings, and stores in shopping malls which are illuminated by the artificial lamps. The initial artificial lamps were the candescent lamps that used the temperature of the fire flame caused by the chemical reaction with oxygen in air. After the discovery of the moving electrons in the materials, the candescent lamps shift to the incandescent lamps that do not use the fire flame. The incandescent lamps generate the significantly high illuminance $\left(\mathrm{lm}, \mathrm{m}^{-2}\right)$ as compared with that of the candescent lamps. The incandescent lamps generate the visible lights by moving electrons in metals, solids, and gases. The lighted incandescent lamps consume the electric energy which is generated at the electric power generators. The electric power generators inevitably release the large amount of the polluted gases and tiny particles (e.g., PM 2.5) into air, giving rise to the polluted air in our life activity. The reduction of the polluted air in our life activity is an urgent task on the world. According to the Paris Agreement on 2016 of United Nation, the target of the reduction of the polluted gases and particles in air is more than $40 \%$ from the present level. The largest sources of the pollution in air at the present time attribute to (i) driving of automobiles and (ii) light sources in the dark. The automobiles are shifting to the electric cars, resulting in the increase in the pollution level from the electric power generators. The change of the automobiles to the electric cars does not reduce the pollution levels in the air on the world. Here we consider a real reduction of the pollution level from the electric power generators on the world by the application of the most advanced incandescent lamps.

According to the reports of COP (Conference of Particles, 2015) of United Nation, the electric power consumption of the lighting lamps on the world is around $31 \%$ of totally generated electric powers on the world. With this reason, we have paid our attention to the real reduction in the electric power consumption of the electric power generators on the world by the application of the incandescent lamps. If the incandescent lamps light on with the zero electric power consumption, we may reduce the $31 \%$ of the electric power consumption on the world.

After the extensive study on the fundamentals of the lighting mechanisms in the incandescent lamps, we have found a candidate that is the coil-EEFL lamps [1]. Under the operation of the external DC electric circuits, the coil-EEFL lamps consume the electric energy that is the nearly zero. Furthermore, the coil-EEFL lamps do not have the consumed materials in the operation, promising the operation life longer than $10^{6}$ hours. As the lamp operates for 24 hours per day, $10^{6}$ hours are longer than 100 years $\left\{=10^{6} \times(24 \times 365)^{-1}=6 \times\right.$ $\left.10^{2}\right\}$. The long operation life of the coil-EEFL lamps also saves the electric power consumption in the production of the 
components of the coil-EEFL lamps. In this report, we will describe the fundamental mechanisms of the invented coil-EEFL lamps [1], even though the development of the coil-EEFL lamps for the production remains as a future study by someone else.

\section{Which Incandescent Lamp Has Potential for Contribution to Green Energy Project}

Incandescent lamps use moving electrons in metals, solids, and gases. We must know which incandescent lamp has the less electric power consumption in the operation. The materials are made by the atoms. The atoms in the materials are actually bounded with the electrons in the uppermost electric shells (s, p, d, and f shells) in the atoms. The bonding conditions of the electrons of the atoms make the different materials.

\subsection{W-filament Lamps}

The metals are formed with the metallic bound with the electrons in either one of $\mathrm{s}, \mathrm{p}, \mathrm{d}$, and $\mathrm{f}$ shells in which the electron shell has a vacancy of the electron. Accordingly, the electrons in the metals move on in the bonding shell of the metal atoms. No vacuum space between atoms involves in the moving electrons in metal. The moving electrons in the metals inevitably generate the Joule Heat that is given by $I^{2} R$. Where $\mathrm{I}$ is electric current, and $\mathrm{R}$ is electric resistance. The $\mathrm{R}$ is determined by the thermal perturbation of the moving electrons from the thermally vibrating atoms at lattice sites. The typical metal lamp is made by the tungsten (W) filament in the vacuum sealed glass bulb. The lights are generated from the heated $\mathrm{W}$-filament at the temperatures higher than $1000^{\circ} \mathrm{C}$. The lighting source of the W-filament lamp is the heated metal that is similar with the lights from the Sun. With this reason, the performance of the W-filament lamps is evaluated with the heated temperatures of the metal filaments by the Joule Heat. One may allow us to have a conclusion that the $\mathrm{W}$-filament lamps do not contribute to the Green Energy Project.

\subsection{LED Lamps}

The lighting mechanisms of the incandescent lamps by the solids and gases quite differ from the metal-filament lamps. The difference comes from the bonding of the atoms. At first, we take the incandescent lamps by the solids that are the compounds formed by the atoms. The compounds, like as III-V compounds, are made by the covalent bounding. The covalent bonding does not have the vacancy in the bounding orbital shell of the atoms. The electron cannot move in the bonding electron shell. For an example, the pure III-V compounds are the electric insulators.

The story is changed with the impure compounds. As the compound contains a very small amount of the impurity (like as IV-atoms), each impurity atom in the III-V compound has one extra electron in the bonding shell. The extra electrons in the impurity atoms stay in the narrow vacuum space between atoms at the lattice sites that are arranged with the separation distance at around $10^{-10} \mathrm{~m}$. As the III-V compound has the metal electrodes at the both ends, the extra electrons may move on in the narrow vacuum under the electric field between the electrodes. Thus the impure compound becomes as the electrically conductive compound. This is n-type III-V semiconductor. As the III-V compounds contain the small amount of the impurity (II-atoms), the bonding shell of the impurity atoms in the III-V compound has an empty of the electron in the upper shell in the bounding atoms. The impurity may pick up the electron from the vacuum space between atoms at lattice sites. The picked electrons by the impurity release to the vacuum between atoms at the lattice sites. The compounds that have the empty of the bounding electrons are called as p-type semiconductor. The n-type and p-type semiconductors are the electric conductor but the moving electrons do not generate the light.

The LED lamps utilize the luminescence centers in the narrow junction layer between n-type and p-type semiconductors. The luminescence centers in the junction act as the recombination centers of the captured electrons and holes. The recombinations of the electrons and holes at the recombination centers generate the visible lights. The colors of the generated lights change with the kinds of the recombination centers. Thus the LED lamps generate the visible photons from the luminescence centers. The LED lamps do not use the lights from the heated materials. The generation mechanisms of the lights from the LED lamps totally differ from that of the $\mathrm{W}$-filament lamps.

Here arises a problem in the operation of the LED lamps. The moving electrons in the narrow vacuum space between atoms in the LED lamps generate the Joule Heat $\left(\mathrm{I}^{2} \mathrm{R}\right)$. The stability of the luminescence centers in the junction has a threshold temperature at $70^{\circ} \mathrm{C}$ [2]. The threshold temperature determines the numbers of the moving electrons, corresponding to the numbers of the visible photons from the LED lamps. The moving electrons in the LED lamps lose some amount of the kinetic energy by the Joule Heat. The luminescence centers in the junction request a threshold kinetic energy of the electrons and holes for the recombinations. Consequently, the numbers of the emitted photons from the LED lamps are less than the numbers of the injected electrons per second. The numbers of the injected holes is the same with the injected electrons. This means the quantum efficiency $\left(\eta_{\mathrm{q}}\right)$ of the generation of the photons by one moving electron in the LED lamps is less than $1.0\left(\eta_{\mathrm{q}}<1.0\right)$ [2]. The reported $\eta_{\mathrm{q}}$ is around 0.5 that one photon is generated by two pairs of the electrons and holes. The low $\eta_{\mathrm{q}}$ and the threshold operation temperature of the LED lamps determine the maximum numbers of the emitted photons per second from the LED lamps. The study on the LED lamps leads us to a conclusion that the LED lamps are definitely not the energy saving lamps to the Green Energy Project of the UN by (a) the Joule Heat, (b) low $\eta_{\mathrm{q}}<1.0$, and (c) the threshold temperature at $70^{\circ} \mathrm{C}$ of the luminescence centers in the junction. 


\subsection{FL Lamps}

The fluorescent (FL) lamps have the quite different story from the LED lamps. The FL lamps use the Ar gas in the vacuum sealed glass tube [3]. The boiling temperature of $\mathrm{Ar}$ is $-186^{\circ} \mathrm{C}$. Ar atoms at above $-185^{\circ} \mathrm{C}$ are in gas phase. Each $\mathrm{Ar}$ atom in gas phase floats in vacuum with a large separation distance. In the conditions of the FL lamps, the separation distance between floating atoms is around $10^{-6} \mathrm{~m}$. Individual Ar atoms are isolated in the Ar gas space.

The floating Ar atoms with the large separation distance do not have the thermal perturbation from the neighboring $\mathrm{Ar}$ atoms. With other word, the moving electrons in the Ar gas space do not have the electric resistance R. Accordingly, the Ar gas space in the lighted FL lamps provide the superconductive vacuum for the moving electron. The superconductive vacuum in the FL lamps is a great advantage as the incandescent lamp. The generation mechanisms of the lights by the moving electrons in the FL lamps quite differ from the LED lamps. The floating $\mathrm{Ar}$ (and $\mathrm{Hg}$ ) atoms are excited by the moving electrons in the superconductive vacuum. The excited $\mathrm{Ar}$ and $\mathrm{Hg}$ atoms ( $\mathrm{Ar}^{*}$ and $\mathrm{Hg}^{*}$ ) emit the lights (photons) for returning to the $\mathrm{Ar}$ and $\mathrm{Hg}$ atoms. The details of the lighting mechanisms are below:

The moving electrons in the superconductive vacuum slightly scatter the moving direction from the electric field $\left(\mathrm{F}_{\mathrm{vec}}\right)$ between cathode and anode. The scattering is caused by the Coulomb's repulsion from the electrons in the upper electron shells of the floating Ar atoms. The moving electrons give some amount of the kinetic energy to the electrons in the upper shell of the Ar atoms by each scattering. The orbital electron received the kinetic energy from the moving electrons escapes to the vacuum space between Ar atoms, leaving ionized $\mathrm{Ar}$ atom $\left(\mathrm{Ar}^{1+}\right)$ at the floating position. $\mathrm{Ar}^{1+}$ does not change the floating position. The escaped electron in the vacuum space is the free electrons (e-) that move on in the superconductive vacuum. Thus the moving electrons in the superconductive vacuum lose some amount of the kinetic energy by the each Coulomb's repulsion. This is the attenuation of the kinetic energy of the moving electrons from the cathode. As the moving electrons lose the kinetic energy to the energy level of the excitation of the Ar atoms, the Coulomb's repulsion results in the excitation of the Ar atom (Ar*). The Ar* emits a photon and returns to Ar atom. As the moving electrons have the kinetic energy smaller than the excitation energy of Ar atom, the moving electrons recombine with $\mathrm{Ar}^{1+}$, returning to Ar atom. Statistically, the Ar gas space in the lighted FL tube always contains the $\mathrm{Ar}^{1+}$, e-, $\mathrm{Ar}^{*}$ and $\mathrm{Ar}$. They are invisible by the naked eyes. Only Ar* emits the sky-blue lights, so that we may monitor them in the volume of the sky-blue lights. By the study with the needle electrodes, the numbers of the injected electrons from the cathode are equal with the numbers of the collected electrons by the anode $[1,4]$. The numbers of the moving electrons in the lighted FL lamps is calculated as $10^{15}$ electrons per second, corresponding to the DC electric current of $10^{-4} \mathrm{~A}\left\{=10^{-19}\right.$ Coulomb x $\left(10^{15}\right.$ per sec $\left.)\right\}[1,4]$. The FL lamps do not use the lights from $\mathrm{Ar}^{*}$. The FL lamps use the excited $\mathrm{Hg}$ atoms $\left(\mathrm{Hg}^{*}\right)$ as the origin of the light source.

When the Ar gas contains the vaporized $\mathrm{Hg}$ atoms, the moving electrons of the kinetic energy between $10.3 \mathrm{eV}$ and $6.7 \mathrm{eV}$ also excite the $\mathrm{Hg}$ atoms $\left(\mathrm{Hg}^{*}\right)$ [3]. The $\mathrm{Hg}^{*}$ emit the invisible UV lights by the naked eyes. The phosphor screen on the inside glass wall of the FL lamps transduce the UV lights to the lights in the visible spectral wavelengths with $\eta_{\mathrm{q}} \approx 1.0$. Therefore, the numbers of the photons of the visible lights from the phosphor screen in the lighted FL lamps have the equal numbers of $\mathrm{Hg}^{*}$ in the $\mathrm{Ar}$ gas space per second. The calculated numbers of the $\mathrm{Hg}^{*}$ by one moving electrons in the Ar gas space in the FL lamp are the astronomically high $\eta_{\mathrm{q}} \approx 10^{11}$ photons per Ar gas space in $1 \mathrm{~m}^{3}$ and per second $[1,4]$. Therefore, the phosphor screen of the FL lamps emit the $10^{26}$ visible photons $\left(\mathrm{m}^{3}, \mathrm{~s}\right)^{-1}\left\{=10^{15} \times 10^{11}\left(\mathrm{~m}^{3}, \mathrm{~s}\right)^{-1}\right\}$. The numbers of the emitted photons from the FL lamp are larger than the stars in our Galaxy that may contain $10^{22}$ stars. The numbers of the lighted photons from the phosphor screen of the FL lamps are confirmed with the numbers of the emitted photons from the commercial 40W-HCFL lamps [1, 4].

We may have a conclusion from the studies described above. Only FL lamps among the incandescent lamps have a potential that contribute to the Green Energy Project. Then, we have concentrated to the study on the more details of the FL lamps.

\section{Hiding of Great Potentials in Studies on Commercial HCFL Lamps for 80 Years}

The commercial HCFL lamps have the long development history for more than 80 years [3]. By the study on the commercial HCFL lamps, we have found that the established technologies of the commercial HCFL lamps contain many unacceptable technologies in the basics. The established technologies are based on the hypotheses, even though the commercial HCFL lamps hold the advantage over other incandescent lamps. The hypotheses in the unacceptable technologies of the HCFL lamps have not yet proved by the scientific evidence before 2010. Therefore, the performance of the commercial HCFL lamps limits for the acceptance. We must clarify the unacceptable technologies of the established HCFL lamps with the advanced scientific evidences in order to reveal the latent potentials of the FL lamps.

The commercial HCFL lamps have studied for more than 80 years by many scientists since the invention [3]. They said that the commercial HCFL lamps are already produced by the mature technologies on 1970. Their conclusion had supported by the annual production volume of the HCFL lamps more than multimillions on the world. The studies for 80 years have summarized in the Hand Books and many published papers. The typical summaries are the references in [5, 6, 7]. After 1980 , there is no new report on the advanced technology in the HCFL lamps, except for our reports after 2010. We have a very hard time for the communications with the scientists and engineers who have learned the established technologies of 
the FL lamps in the text books. Especially, it was the very hard time for the publications of the professional Journals with the reviewers who have leaned from the text books. If you just lean the text books, your brain is a just a computer. For the understanding of the really advanced FL lamps, they must wash out the unacceptable technologies of the HCFL lamps from their memory in the brain.

We had a chance to study of the FL lamps on 2007. We had many questions on the fundamentals of the lighting mechanisms of the established HCFL lamps. By the careful studies on the established HCFL lamps by the knowledge of the developed solid-state physics, gases and vacuum, we have found that the established technologies of the HCFL lamps before 2007 stay at the premature technologies based on the hypotheses of the observed results by the experiments.

The premature technologies relate to the followings: (i) The ignorance of the floating Ar atoms in wide vacuum $[1,4]$. (ii) The vacuum between Ar atoms in unlighted FL lamps fills up with the negative electric field [1, 4]. (iii) After the formation of the internal DC electric circuit, the vacuum in the lighted FL lamps suddenly changes to the superconductive vacuum for the moving electrons in the Ar gas space [1,4]. (iv) The real electron sources in the commercial HCFL lamps are the high temperature (above $50^{\circ} \mathrm{C}$ ) Ar corona space (HTACS) that are formed in Ar gas space. The HTACS is the 4G electron sources [8]. (v) The electron sources in the CCFL lamps are the volume of the glow lights on the polarized phosphor screen that is the $3 \mathrm{G}$ electron sources [9]. (vi) The electrons in the lighted FL lamps never reach on the surface of the phosphor screen [10]. (vii) The electrons only move on in the positive column in Ar gas space [10]. (viii) Naturally, there is the gap between the positive column and phosphor screen [10]. (ix) The depths of the gap severely control the performance of the light-output from the phosphor screen in the lighted FL lamps [11]. (x) Coexistence of disparities of the external AC driving circuit and internal DC electric circuit in the operation in FL lamps $[11,12]$. And (xi) the erroneous concepts of the $\mathrm{W}_{\text {act }}$ of the AC driving circuit for the generation of the lights in the HCFL lamps [13]. The details of the unacceptable technologies are below:

\subsection{Each Ar Atom Floats in Vacuum with Wide Separation Distance Between Ar Atoms}

The fundamental errors come from the ignorance of the peculiar property of the Ar gas phase. The vacuum space between Ar atoms in gas phase quite differs from the narrow vacuum between atoms at lattice sites in metals and solids. In the past, the scientists and engineers had believed that the Ar gas space in the FL lamps is the electric conductor, like as the metals and conductive solids $[5,6,7]$. This is the fundamental error. Ar atoms in FL lamps do not bind up each other with the bounding electrons in the electric shell of the Ar atoms. Each Ar atom in FL lamps floats in the wide vacuum space with the Maxwell-Boltzmann Distribution. We may calculate the separation distance between $\mathrm{Ar}$ atoms from the Maxwell-Boltzmann Distribution. It is longer than $10^{-7} \mathrm{~m}[1$, 4]. The light source in the FL lamps originates from the excited $\mathrm{Hg}$ atoms $\left(\mathrm{Hg}^{*}\right)$ (about $10^{-3}$ time of $\mathrm{Ar}^{*}$ at $40^{\circ} \mathrm{C}$ by the moving electrons in the Ar gas space. The $\mathrm{Hg}^{*}$ emit the strong ultraviolet (UV) lights at around $254 \mathrm{~nm}$ and the weak UV light at $183 \mathrm{~nm}$. Phosphor screen on inner glass wall of the FL lamps transduces the UV lights to the visible lights with the $\eta_{\mathrm{q}}$ $\approx 1.0$.

The wave function of the Ar atoms in the vacuum at the pressures less than $10^{4} \mathrm{~Pa}$ ( $\leq 70$ Torr) isolate each other with the large separation distance wider than $10^{-7} \mathrm{~m}$. You may simply confirm the isolated Ar atoms in the vacuum of the FL lamps by the measurements of the absorption (and emission) spectrum of the Ar gas by the high resolution spectrometer. The detected spectrum consists with the sharp lines, indicating that the isolation of the wave function of the floating Ar atoms in the vacuum. The detected spectrum also informs us that each intrinsic absorption (and emission) line splits into the sublevels by the Stark Effect. The Stark Effect is the splitting of the intrinsic energy levels under the electric field. The measured results surely indicate that the vacuum between floating Ar atoms fills up with the electric field from the electrons in the upper shells of the Ar atoms. The vacuum between Ar atoms in the Ar gas is the electric insulator, like as the air. The electrons from the metal cathode in the FL lamps never step in the vacuum that fills up with the negative electric field. The negative electric field in the vacuum between floating Ar atoms should be electrically neutralized in the lighted FL lamps. The electrical neutralization in the vacuum is made by the presence of $\mathrm{Ar}^{1+}$ in the Ar gas space. After the neutralization, the vacuum between floating $\mathrm{Ar}$ atoms becomes the superconductive vacuum for the moving electrons in the lighted FL lamps. The vacuum in the unlighted FL lamps has the negative field.

As the references, we may obtain the absorption bands with the thin solids. In the solids, the atoms occupy at the lattice sites with the separation distances at $10^{-9} \mathrm{~m}$. The absorption bands of the solids indicate the overlapping of the wave function of the atoms at the lattice sites. In the case of many solids, the anode on the conductive solids may directly inject the electrons into the narrow vacuum space between atoms at lattice sites and the cathode corrects the electrons from the vacuum. Since the operation condition of the FL lamps quite differs from the solids lamps, we cannot take the concepts of the solid-state physics to the analysis of the moving electrons in the Ar gas space of the HCFL lamps. The direct injection of the electrons to the Ar gas space from the metal electrodes of the HCFL lamps is the fundamental error in the study on the FL lamps.

\subsection{Never Injection of Thermoelectrons from Heated $\mathrm{BaO}$ Particles to Ar Gas Space in HCFL Lamp}

As described above, the electrodes of the HCFL lamps never inject the electrons into the vacuum between floating Ar atoms. However, it has stubbornly believed that the heated $\mathrm{BaO}$ particles on the tungsten (W) filament coils in the HCFL lamps directly inject the thermoelectrons into the Ar gas space for more 80 years $[5,6,7]$. This is a hypothesis without the scientific proof. In reality, the hotcathode (HC) on the FL lamps 
never inject the electrons into the vacuum in the Ar gas space. The $\mathrm{HC}$ heats up the nearby $\mathrm{Ar}$ gas space to the temperatures at around $50^{\circ} \mathrm{C}$ for the reduction of the ionization energy of the heated Ar atoms. The hotcathodes are their delusion.

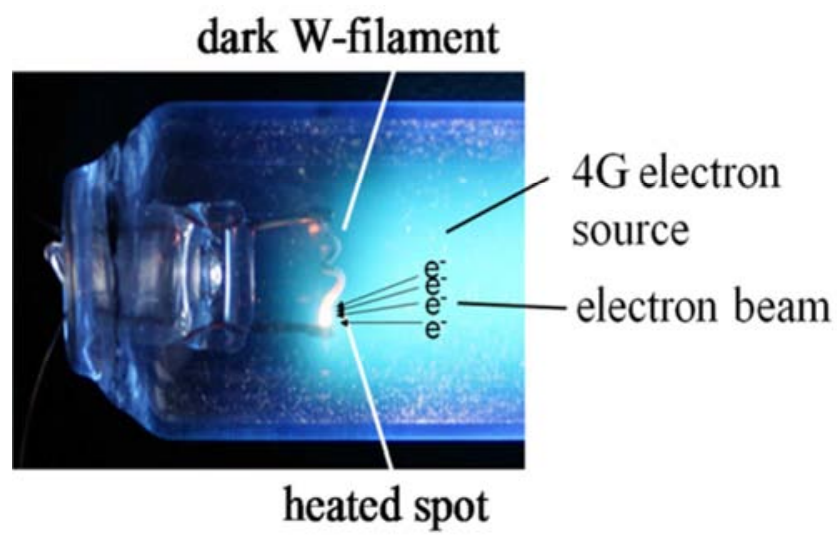

Figure 1. Shows photopicture of working $W$-filament coil at one end of HCFL lamp. Heated area is one end of $W$-filament coil and the rest area is unheated in lighted HCFL lamp.

Figure 1 shows photopicture of a typical working W-filament coil of the HCFL lamp. You may see the large area of the W-filament coil does not heat up the temperature. The limited area at one end of the $\mathrm{W}$-filament coil always heat up to temperatures above $500^{\circ} \mathrm{C}$. If the bear $\mathrm{W}$-filament coil has a large area, the bear W-filament coil does not heat up the temperature. The heated spot of the $\mathrm{W}$-filament coil confine the edge of the bear $\mathrm{W}$-filament spot that is covered with the $\mathrm{BaO}$ particles. The bear $\mathrm{W}$-filament coil with the $\mathrm{BaO}$ particles heats up by the irradiation of the electron beam (streamer electrons) from the $4 \mathrm{G}$ electron source that is the high temperature Ar corona space (HTACS) [8]. The HTACS at the both ends of the lighted FL lamp work as the cathode and anode of the internal DC electric circuit in the lighted FL lamps. The electron beam current from the HTACS is around 4 $\mathrm{x} 10^{-4} \mathrm{~A}$ in the spot diameter less than $1 \times 10^{-3} \mathrm{~m}$.

The heated spot on the $\mathrm{W}$-filament coil is periodically heated as the $\mathrm{W}$-filament has the positive potential. The spot is not heated as the $\mathrm{W}$-filament coil has the negative potential. The $\mathrm{BaO}$ particles have the large heat capacity. The heated $\mathrm{BaO}$ particles at around the heated spot hold the required temperature for the subsequent half cycle. The sizes of the heated area of the $\mathrm{W}$-filament coil are changed with the diameter of the $\mathrm{W}$-filament and the amount of the coated $\mathrm{BaO}$ particles on the W-filament coil. The commercial HCFL lamps do not controlled the both of them with the misunderstanding of the mechanisms of the $\mathrm{W}$-filament coil with the $\mathrm{BaO}$ particles for 80 years. Figure 2 shows the temperature profile of the heated Ar gas space in the lighted HCFL lamp. The temperatures have measured by the infrared thermometer. If the HCFL lamps heat up in the oven to the temperature at $50^{\circ} \mathrm{C}$ for 30 minutes, the heated HCFL lamps weakly light up by the attachment of your fingers in the dried room. But the HCFL lamps at room temperature do not lights up by the attachment of your fingers. The results in Figure 2 support the HTACS as the cathode and anode of the internal DC electric circuit that is formed in the Ar gas space of the lighted HCFL lamps. The conclusion is supported by the study on the other vacuum devices.

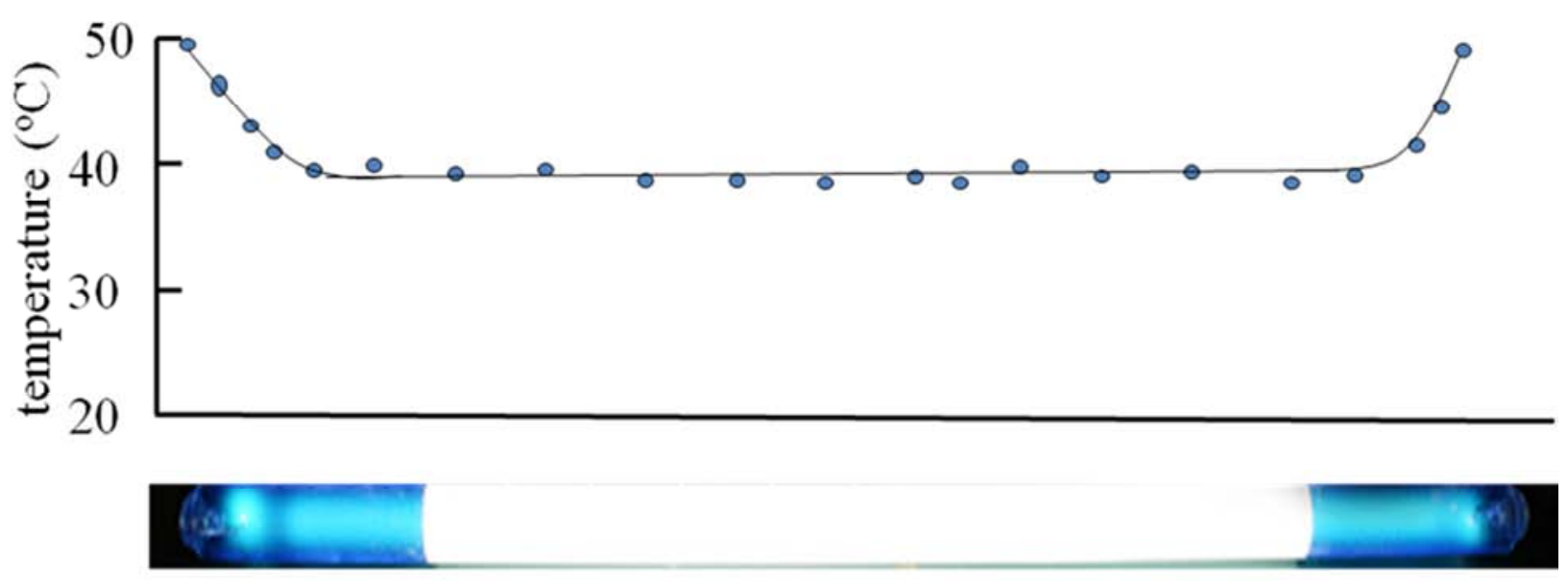

\section{thermometer : Venter 350}

Figure 2. Shows temperature profile of heated Ar gas space of lighted HCFL lamp. The temperatures of Argas space are determined by thermometer that determines temperatures by infrared lights.

The drilled study of the thermoelectron emission from the $\mathrm{Ba}$ atoms on top layer of the heated $\mathrm{BaO}$ layers on the metal had made with the developments of the cathode-ray tubes (CRT) and vacuum (radio) tubes (VT). According to the study on the $\mathrm{CRT}$ and VT, only $\mathrm{Ba}$ atoms on the heated $\mathrm{BaO}$ layers steadily emit the thermoelectrons into the vacuum at the pressures less than $10^{-5} \mathrm{~Pa}\left(<10^{-7}\right.$ Torr $)$. Under the vacuum pressures higher than $10^{-2} \mathrm{~Pa}\left(>10^{-4} \mathrm{Torr}\right)$, the heated $\mathrm{Ba}$ atoms never emit the thermoelectrons. The Ar gas pressures of the commercial HCFL lamps are higher than $665 \mathrm{~Pa}$ (= 5 Torr). Furthermore, the commercial HCFL lamps always contain a large amount of the residual gases higher than $133 \mathrm{~Pa}$ ( $>1$ Torr). 
The residual gases come from the poorly designed production facilities. Furthermore, especially Asian Countries, the operation conditions of the furnace and vacuum sealing process of the pumping glass tubes are so poor [1]. With this reason, the engineers of the HCFL lamp never produce the high quality of the HCFL lamps. The misunderstanding of the thermoelectrons from the $\mathrm{BaO}$ particles led them to a wrong trail for the study on the HCFL lamps. The residual gases in the produced HCFL lamps generate the flickering lights. The flickers disappear from the lighted HCFL lamps. The disappearance of the flickers is caused by the adsorption of the $\mathrm{CHn}$ gases on the phosphor screen. This is a reason that the aging process has taken in the produced HCFL lamps. As the produced HCFL lamps do not contaminated with the residual gases, the aging process is unnecessary for the HCFL lamps.

As describe above, the thermoelectron emission in the HCFL lamps is the delusion. The reality is the formation of the $4 \mathrm{G}$ electron source in the Ar gas space [8]. The residual gases in the commercial HCFL lamps generate the serious problems for the production of the coil-EEFL lamps.

\subsection{Residual Gas in Produced HCFL Lamps}

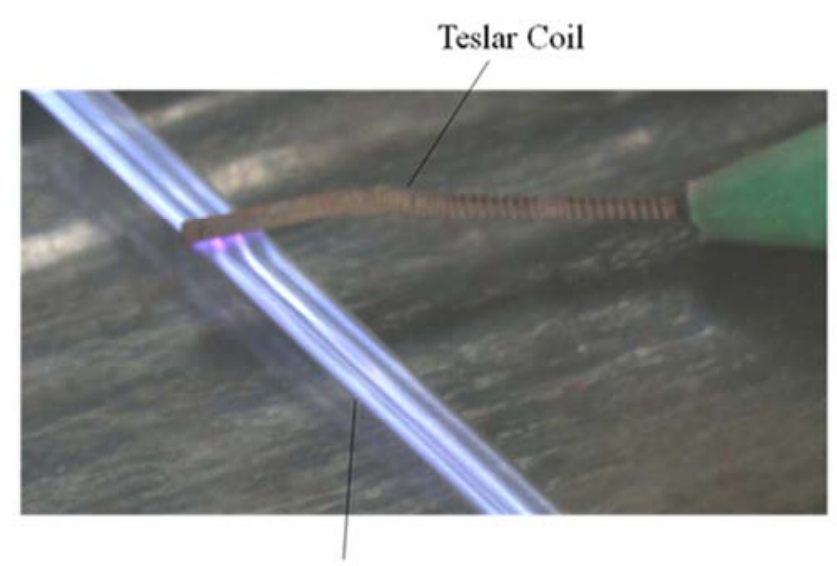

vacuum-sealed glass tubes after pumping process

Figure 3. Photopicture of brilliantly lighted residual gases in vacuum-sealed glass tubes under Tesla Coil. Testing glass tubes are made by vacuum-seal after pumping process of production of HCFL lamps in many Asian Countries. The details are in text.

You must know where comes the residual gases in the FL lamps? You can be detected by the followings. You have the glass tubes for the HCFL lamps without phosphor screen and electrodes at the both ends. The glass tubes should be experienced all production process of the HCFL lamps. After the end of the all pumping process, you may test the glass tubes on the pumping facility at the room temperature by the Tesla Coil. You may not detect the light from the glass tubes. Then the glass tubes seal off from the pumping facility. You may test again the vacuum-sealed glass tubes under the Tesla Coil. You surely detect the brilliant lights from the vacuum-sealed glass tubes.

Figure 3 shows the photopicture of the visible lights from the vacuum-sealed glass tubes under the Tesla Coil. The kinds of the residual gases can be determined by the colors of the lights. The similar results are obtained with many FL lamp productions in the Asian Countries. You must find a way of no light from the vacuum-sealed glass tubes before the setting of the production lines of the HCFL lamps. This is an engineering subject. We like to provide the fundamental information of the degassing data for the vacuum-seal in your study with the referring the following Figures.
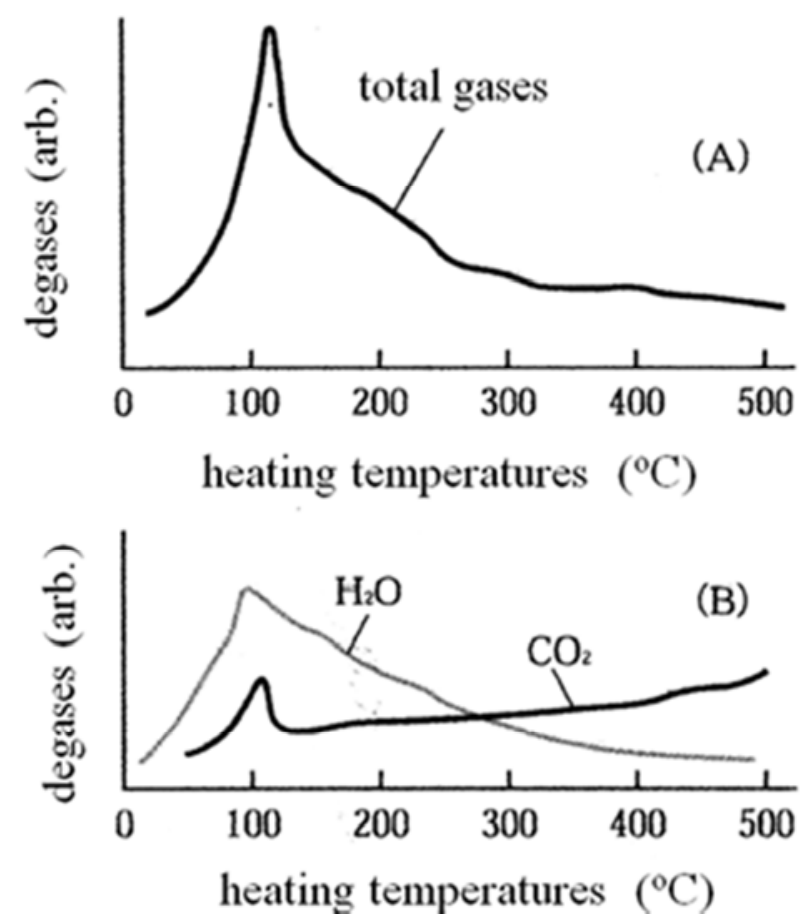

Figure 4. Shows degassing data from heated glass tube of HCFL lamps. (A) is the total gases from glass tube. (B) shows vapor of water $\left(\mathrm{H}_{2} \mathrm{O}\right)$ and carbon oxide $\left(\mathrm{CO}_{2}\right)$ gases as a function of heating temperatures of glass tube.

Figure 4 shows the degassing data from the glass tube at the heating temperatures of the pumping furnace. As shown in curve (A) in Figure 4, the large amount of the gases releases from the heating glass tube at $100^{\circ} \mathrm{C}$ and then the released gases decreases with the temperatures up to $350^{\circ} \mathrm{C}$. The released gases come from the trapped gases in the vacancies in the surface volume of the inner glass wall. The majorities of the released gases are water $\left(\mathrm{H}_{2} \mathrm{O}\right)$ and carbon dioxide $\left(\mathrm{CO}_{2}\right)$ as shown in (B). The vacancies in the surface volume of the glass tube also adsorb the air $\left(\mathrm{N}_{2}\right.$ and $\left.\mathrm{O}_{2}\right)$ but they are a small amount as compared with the ordinal detection. The degassing process is usually made at the temperature at around $400^{\circ} \mathrm{C}$. Here is the problem in Asian Countries. The temperatures in Figure 4 are the temperatures of the glass tubes, and are not the furnace temperatures. The glass tubes are good thermal insulator. The heated furnace should be uniformly heat up all area of the FL glass tubes in the furnace. This is a very important consideration in the production of the FL lamps. The reality differs from the requirement. The bottom of the furnace does not have heaters. Furthermore, the heaters on the side wall are not covered with heat scatters. You should consider the uniformity of the heat of the whole FL glass tube in the furnace, and does not control the temperatures at the control panel. 


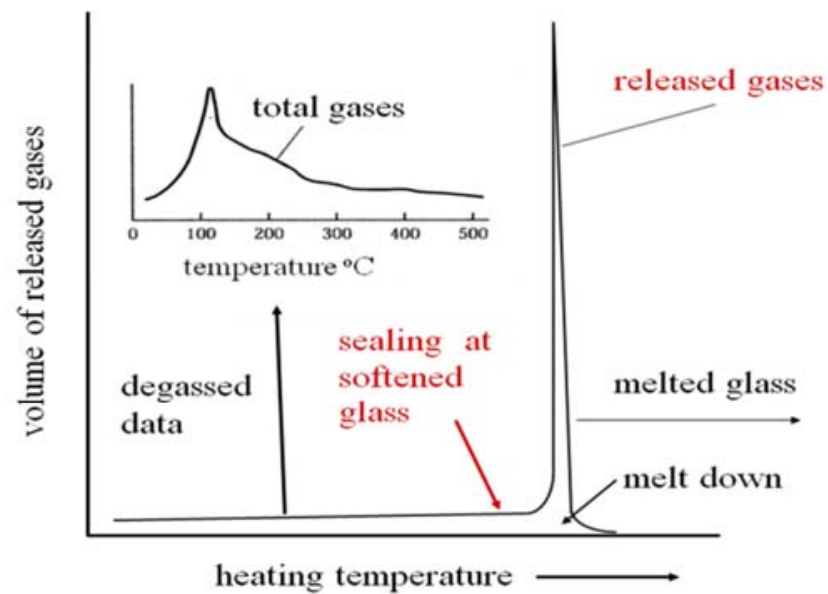

Figure 5. Shows wide degassing curves from heated glass tube of HCFL lamps. After degassing process, the narrow glass tube for pumping of HCFL tubes is sealed by melt conditions. There are two temperature ranges. One is sealed off by melted glass and other is sealed at softened temperature.

The majority of the residual gases as shown in Figure 3 come from the vacuum-sealing process. Figure 5 shows the released gas pressures up to the above melted temperature of the glass tube. The vacuum-seal of the processed FL lamps has been made with the melted temperature of the glass tube. This is the wrong sealing. The melted glass tubes instantly releases an extremely large amount gases from the volume of the melted glass tube. The trapped residual gases in the produced FL lamps significantly reduce to a low level by the sealing temperatures below the melting temperature. The improved coil-EEFL lamps are produced with the less residual gases.

\subsection{No Involvement of Active Power Consumption ( $\left.W_{\text {act }}\right)$ in Generation of Lights from HCFL Lamps}

The determination of the electric power consumption by the AC active consumption ( $\mathrm{W}_{\text {act }}$ ) is a big mistake in the study on the FL lamps. Never evaluate the performance of the FL lamps by $\mathrm{W}_{\text {act. }}$. The reason is below: The HCFL lamps are operated with the AC driving circuit. The commercial 40W-HCFL lamps can be operated with the DC driving circuit with the very low $\mathrm{DC}$ power consumption $\left(\mathrm{W}_{\mathrm{DC}}\right.$ ) less than 1 watt with the same illuminance under the AC driving circuit. Under the DC operation, the metal electrodes are electrically closed with the DC streamer electron beam in the Ar gas space that is $4 \mathrm{x}$ $10^{-4} \mathrm{~A}$ maximum as illustrated in Figure 1. The bear W-filament continuously evaporates from the anode filament, giving rise to the short operation life, less than 100 hours. With this reason, the HCFL lamps are operated with the AC driving circuit with the large $\mathrm{AC}$ active power consumption $\left(\mathrm{W}_{\mathrm{act}}\right)$ of many commercial HCFL lamps. The large $\mathrm{W}_{\mathrm{act}}$ is determined by the voltage and $\mathrm{AC}$ induced current at the electrodes, neglecting the real $\mathrm{W}_{\text {act }}$ of the external $\mathrm{AC}$ driving circuit. The real $\mathrm{W}_{\text {act }}$ of the $40 \mathrm{~W}-\mathrm{HCFL}$ lamps is more than 80 watt with the chock-coil, and is 60 watt with the inverter [4].

As already described 3-2, the electrodes of the HCFL lamps never inject the thermoelectrons into the Ar gas space. The $\mathrm{W}_{\text {act }}$ is determined by the induced $\mathrm{AC}$ current. The induced $\mathrm{AC}$ current is not related with the generation energy of the lights from the HCFL lamps. However, the commercial FL lamps have evaluated by the $\mathrm{W}_{\text {act }}$ for more than 80 years $[5,6$, 7]. For example, the commercial $40 \mathrm{~W}-\mathrm{HCFL}$ lamps generate the lights with the electric power consumption of the $\mathrm{W}_{\text {act }}=40$ watt. This is a totally wrong in the study on the FL lamps. The $\mathrm{W}_{\text {act }}$ is given by the induced $\mathrm{AC}$ current. The induced $\mathrm{AC}$ current is not by the electron flow in the Ar gas space [1,4]. The AC current at the electrodes corresponds to the picking up the synchronous displacement of the electrons in the orbital electron shell of the $\mathrm{Ar}^{1+}$ that forms the capacitor $\left(\mathrm{C}_{\mathrm{Ar}}\right)$ under the $\mathrm{AC}$ operation. We must clarify the erroneous evaluation of the FL lamps by the $\mathrm{W}_{\text {act }}$.

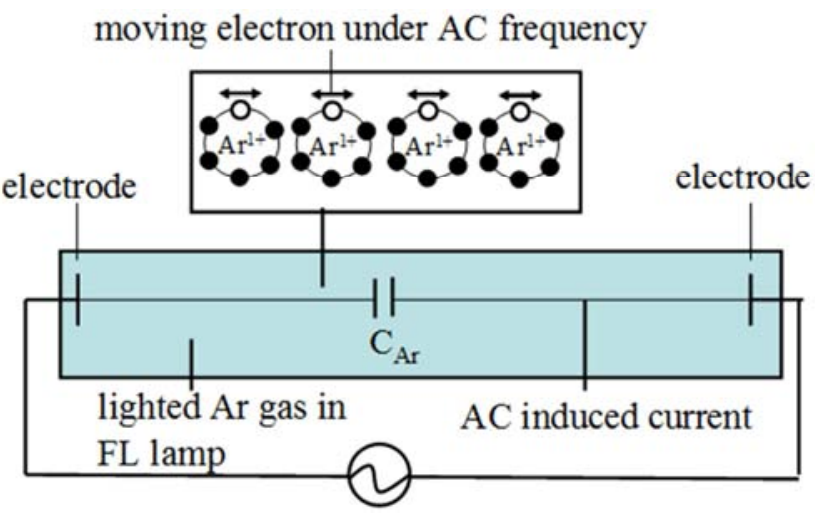

Figure 6. Schematic illustration of formation of $C_{A r}$ and $A C$ induced current at electrodes under $A C$ driving circuit.

Figure 6 illustrates the formation mechanisms of the $\mathrm{C}_{\mathrm{Ar}}$ in the lighted HCFL lamp. The electrodes at the both ends of the HCFL lamps synchronously detect the induced current, not the electron flow, from the displacing electrons in the inside of the orbital shells in the $\mathrm{Ar}^{1+}$ in the lighted HCFL lamps [13]. The confusion comes from the ignorance of the fundamental mechanisms of the capacitor $\left(\mathrm{C}_{\mathrm{Ar}}\right)$ under the operation of the AC electric driving circuits [11]. The studies of the HCFL lamps in the past neglect the most fundamentals of the AC driving circuit having the $\mathrm{C}_{\mathrm{AR}}$.

Now it is clear that the $\mathrm{W}_{\text {act }}$ is not related with the generation energy of the lights in the Ar gas space of the HCFL lamps. The established technologies of the lighted HCFL lamps have evaluated the $\mathrm{W}_{\text {act }}$ as the generation energy of the lights from the HCFL lamps $[4,5,6]$. This is a fundamental error in the study on the HCFL lamps in the past. For the clarification of the real technology of the FL lamps, we may take the revised lighting mechanisms of the FL lamps.

\section{Revised Lighting Mechanisms of FL Lamps}

Now we make the revised lighting mechanisms of the FL lamps. The lights in the FL lamps are originated by the excitation of the $\mathrm{Ar}$ (and $\mathrm{Hg}$ ) atoms by moving electrons in the superconductive vacuum between Ar atoms. The moving electrons in the lighted FL lamps only form in the internal DC electric circuit in the Ar gas space. 


\subsection{Coexistence of Disparity of External Electric Driving Circuit and Internal DC Electric Circuit in Operation of FL Lamps}

As shown in Figure 6, the electrodes at the HCFL lamps are closed with the induced $\mathrm{AC}$ current from the $\mathrm{C}_{\mathrm{Ar}}$. The electrodes at the FL lamp never close with the electron flow in the vacuum in the Ar gas space. The puzzle has solved by the finding of the internal DC electric circuit in the Ar gas space. In the ordinal HCFL lamps, the internal DC electric circuit is covered by the opaque phosphor screen, so that the internal DC electric circuit is invisible by the naked eyes. It has found that the FL lamps are operated with the coexistence of the disparities of the external AC driving circuit and internal DC electric circuit. The two circuits are conjugated with the electric field from the electrodes of the external AC driving circuit [12]. There is no electron flow between two circuits.

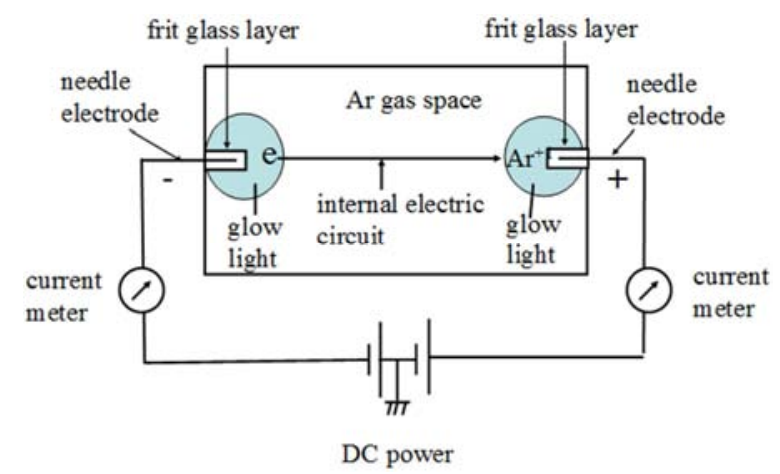

Figure 7. Schematic illustration of formation of internal DC electric circuit in Ar gas space of lighted FL lamps. Details are in text.

The formation of the internal DC electric circuit in the lighted FL lamps can be studied by the needle electrodes in the FL lamp without the phosphor screen [1]. We have observed the glow lights on the needle electrodes. The needle electrodes are respectively covered with the volume of the glow lights at the electric potentials above $1.0 \mathrm{kV}$. We detect the DC current at the both sides of the cathode and anode needle electrodes. When the needle electrodes are covered with thin frit glass layer, the volumes of the glow lights remain on the needle electrodes without the DC current from the needle electrodes. The volumes of the glow lights are formed on the frit glass layer without the supplement of the electrons from the needle electrons. The frit glass layer on the needle electrodes may be polarized under the electric field from the needle electrodes. The volumes of the glow lights on the frit glass layers respectively form the cathode and anode of the internal DC electric circuit. In this case, the needle electrodes do not supply and do not correct the electrons from the volume of the glow lights. Figure 7 illustrates the internal DC electric circuit by the glow lights on the frit glass layers that are covered by the needle metal electrodes. The volume of the glow light on the needle electrode (-) acts as the cathode and the volume of the glow light on needle electrode $(+)$ acts as the anode of the internal DC electric circuit in the Ar gas space in the lighted FL lamps [11].

Now it is very clear that there is no electron flow between the external electric circuit and the internal DC electric circuit.
In the Ar gas space, the electrons move from the cathode to the anode. The moving electrons in the Ar gas space is monitored with the sky-blue lights from the excited $\mathrm{Ar}$ atoms $\left(\mathrm{Ar}^{*}\right)$. The arrived electrons to the anode recombine with the $\mathrm{Ar}^{1+}$ to return to Ar atoms. By the recombination of the electrons and $\mathrm{Ar}^{1+}$, the internal DC electric circuit is closed. The advantage of the internal DC electric circuit is no loose of the Ar atoms in the operation of the FL lamps, promising the operation life longer than $10^{6}$ hours. The lights from the FL lamps are generated by the excited $\mathrm{Ar}$ (and $\mathrm{Hg}$ ) atoms by the moving electrons in the internal DC electric circuit in the lighted FL lamps. We have found the new lighting model of the FL lamps.

\subsection{Development Coil-EEFL Lamps}

The phosphor particles are the polycrystalline particles. As the phosphor particles are grown under the well controlled conditions [13], the polycrystalline phosphor particles have many sharp edge lines and sharp points. Figure 8 shows the photograph of the phosphor particles under the scanning electron microscope (x 2000).

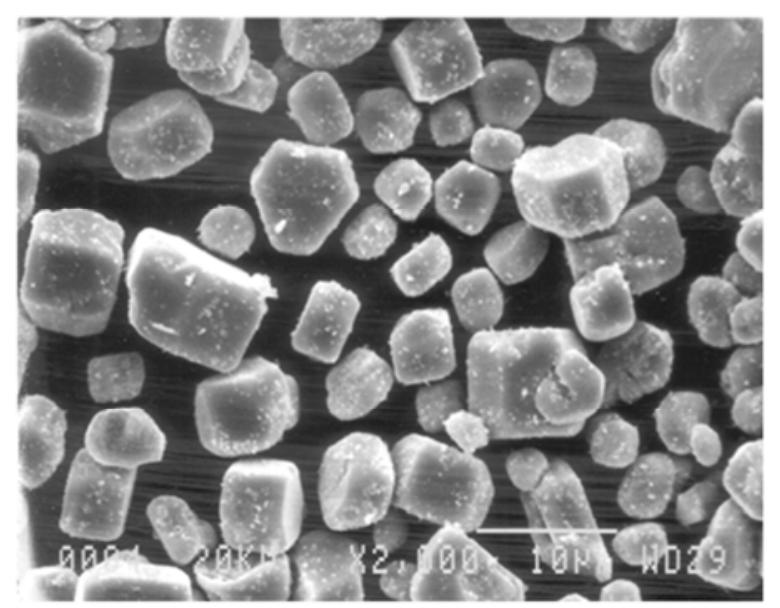

Figure 8. Photograph of phosphor particles under scanning electron microscope $(x 2,000)$.

The practical phosphor particles are the unsymmetrical crystals that are able to deform the crystal structure under the electric field from the electrodes on the outside of the FL glass tube. The deformed phosphor particles are the polarized particles. The polarized phosphor particles may have many sharp edges and points that are the equivalent with the needle electrodes. We have had many difficulties of the electrodes on the outer glass wall of the FL lamps, with the vacuum break under the metal electrodes. Finally, we have found the coil-EEFL lamps that the electrodes are made by the lead wire covered by the plastic. Figure 9 shows photographs of the prototype of the coil-EEFL lamps that are modified from the commercial CCFL lamp and HCFL lamps. The coil-EEFL lamps are operated with the DC $4 \mathrm{kV}$ with the zero electric current. Consequently, $\mathrm{W}_{\mathrm{DC}}=0$. This means no involvement of the $\mathrm{C}_{\mathrm{Ar}}$ in the operation. You may increase the numbers of the coil-EEFL lamps (B) in the parallel connection with the $\mathrm{W}_{\mathrm{DC}}=$ 0 . The thickness of the glow lights on the phosphor screen is 
around $4 \times 10^{-3} \mathrm{~m}$, so that the preferable diameters of the coil-EEFL lamps are less than $1 \times 10^{-2} \mathrm{~m}(\mathrm{~T}-3)$. Since the production of the coil-EEFL lamps requires many items for the optimization. The optimizations of the coil-EEFL lamps remain as a future study by someone else. Here we will describe the preparation of the prototype of the coil-EEFL lamps.

(A)

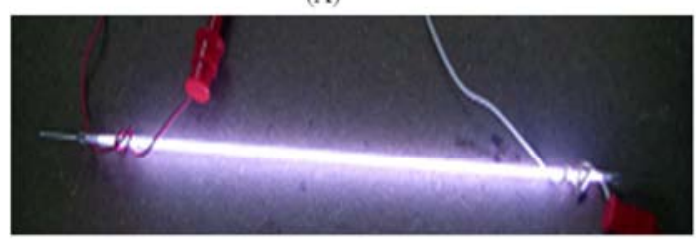

(B)

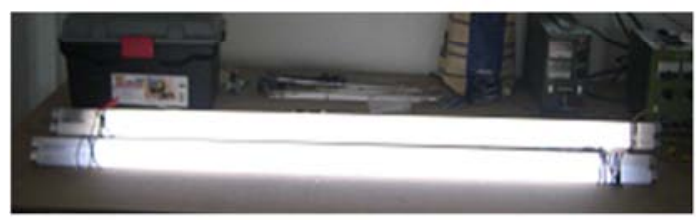

Figure 9. Photographs of experimental coil-EEFL lamps. (A) is single coil-EEFL lamp in diameter at $6 \times 10^{-3} \mathrm{~m}(T-2)$, and (B) is parallel connection of coil-EEFL lamps that are converted from commercial 40W-HCFL lamps at $3.2 \times 10^{-2} \mathrm{~m}$ diameter (T-10). Coil-EEFL lamps are operated with $D C 4 \mathrm{kV}$ with zero DC electric current.

\subsection{Deep Gap Between Positive Column and Phosphor Screen Determines Apparent-Temperature of FL Lamps at $40^{\circ} \mathrm{C}$}

The optimal operation temperature of the commercial HCFL lamps have not made for last 80 years with a difficulty of a trail of the moving electrons in the vacuum space in the Ar gas space of lighted FL lamps. We have found that the electrons do not move on in the entire area of the vacuum in the Ar gas space. The electrons only move on in the limited volume of the Ar gas that is defined as the positive column. The diameter of the positive column is narrower than the inner diameter of the FL lamps. Naturally, there is a gap between positive column and phosphor screen in the lighted FL lamps. Figure 10 illustrates the gap between positive column and phosphor screen on the lighted FL tube. Although the commercial HCFL lamps have the deep gap $\left(3 \times 10^{-3} \mathrm{~m}\right)$, the study on the gaps of the commercial HCFL lamps has not made for more than 80 years. The deep gaps in the lighted FL lamps seriously work as the negative factors in the operation of the FL lamps.

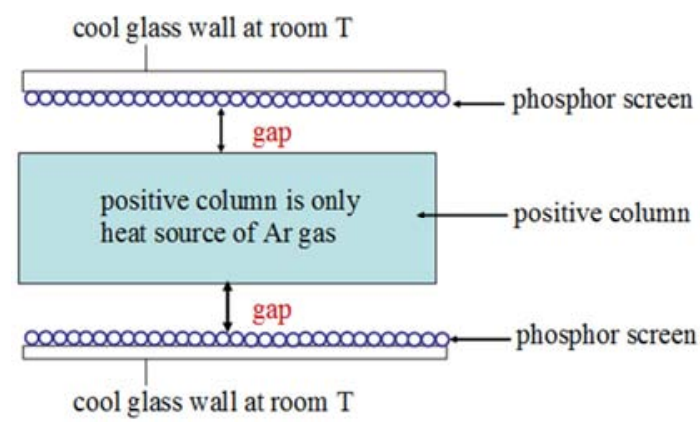

Figure 10. Illustration of gap between positive column and phosphor screen in lighted FL lamp.
We may calculate the inner volume $\left(\mathrm{V}_{\mathrm{FL}}\right)$ of the $40 \mathrm{~W}-\mathrm{HCFL}$ lamp in $1 \mathrm{~m}$ length. The $\mathrm{V}_{\mathrm{FL}}$ is $7.1 \times 10^{-4} \mathrm{~m}^{3}\left\{=\pi \times\left\{\left(3.0 \times 2^{-1}\right.\right.\right.$ $\left.\left.\mathrm{x} 10^{-2} \mathrm{~m}\right)^{2} \times 1 \mathrm{~m}\right\}$. The volume of the positive column $\mathrm{V}_{\text {posi }}$ is $3.5 \times 10^{-4} \mathrm{~m}^{3}\left\{=\pi \times\left(2.2 \times 2^{-1} \times 10^{-2} \mathrm{~m}\right)^{2} \times 1 \mathrm{~m}\right\}$. The volume of the gap $\mathrm{V}_{\text {gap }}$ is given by $3.6 \times 10^{-4} \mathrm{~m}^{3}\left\{=\left(7.1 \times 10^{-4} \mathrm{~m}^{3}\right)-(3.5\right.$ $\left.\left.\mathrm{x} 10^{-4} \mathrm{~m}^{3}\right)\right\}$. The calculations indicate $\mathrm{V}_{\mathrm{gap}} \approx 0.5 \mathrm{~V}_{\mathrm{FL}}$, and $\mathrm{V}_{\text {gap }} \approx \mathrm{V}_{\text {posi. }}$. The UV lights in the 40W-HCFL lamp are generated in the $\mathrm{V}_{\text {posi }}$ that is a half-volume of the $40 \mathrm{~W}-\mathrm{HCFL}$ tube $\left(\mathrm{V}_{\text {posi }} \approx 0.5 \mathrm{~V}_{\mathrm{FL}}\right)$. Another half-volume contains the Ar gas at $10^{3} \mathrm{~Pa}$ (7 Torr) and vaporized $\mathrm{Hg}$ atoms at around at $1 \mathrm{~Pa}$ (7 $\mathrm{x} 10^{-3}$ Torr). The Ar gases in the gap work as the negative factors for the lights from the phosphor screen of the FL lamps.

We first take the vaporized $\mathrm{Hg}$ vapor in the positive column. The illuminance $\left(1 \mathrm{~m}, \mathrm{~m}^{-2}\right)$ of the lighted $\mathrm{FL}$ lamps is determined by the amount of the vaporized $\mathrm{Hg}$ atoms in the positive column from the $\mathrm{Hg}$ droplets on the phosphor screen. The Hg droplets on the phosphor screen should heat up to a required temperature. The heat source in the lighted FL lamps is only ionization of the Ar atoms by the moving electrons in the positive column. The ionization of the Ar atoms in the positive column releases the heat by the change in the entropy.

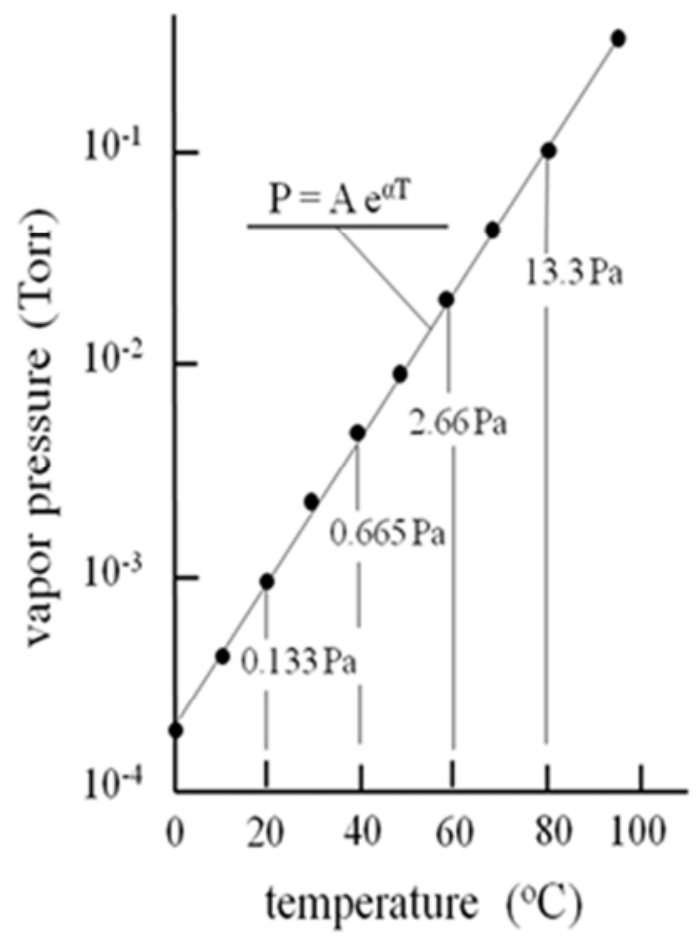

Figure 11. Vapor pressures of Hg atoms as a function of heated temperatures of $\mathrm{Hg}$ droplets on phosphor screen.

Figure 11 shows the vapor pressures of the $\mathrm{Hg}$ atoms as a function of the heating temperatures of the $\mathrm{Hg}$ droplets. The vapor pressures of $\mathrm{Hg}$ atoms exponentially increase with the heating temperatures of the droplets on the phosphor screen. However, the commercial HCFL lamps claim the optimal temperature at $40^{\circ} \mathrm{C}[5,6,7]$. Since the $\mathrm{Ar}$ gas in the gap has the thermal conduction of $3.9 \times 10^{-5} \mathrm{cal}(\mathrm{cm}, \mathrm{sec}, \mathrm{deg})^{-1}$ that is the good thermal insulator. According to the results in Figure 11, the optimal temperature at $40^{\circ} \mathrm{C}$ is an apparent temperature. 
This is because the outer glass wall of the FL lamps is cooled by the air convection at the room temperature $\left(22^{\circ} \mathrm{C}\right)$. There is a large temperature gradient between positive column $\left(40^{\circ} \mathrm{C}\right)$ and phosphor screen $\left(22^{\circ} \mathrm{C}\right)$. The temperature gradient may reduce with the shallow gap. As described later, the depth of the gap between positive column and phosphor screen can be reduced by the special arrangement of the low voltage CL phosphor particles on the top layer on the phosphor screen. We have reduced the depth of the gap to $5 \times 10^{-4} \mathrm{~m}$. Then, the FL lamps increase the illuminance $\left(\mathrm{lm}, \mathrm{m}^{-2}\right)$ about $30 \%$. However, there is still temperature gradient in the gap by the cooling of the phosphor screen by the convection of the cool air at the room. For the complete elimination of the temperature gradient in the gap, the lighted FL lamps should put in the vacuum-sealed glass tube. The developed FL lamps set in the vacuum-sealed container. The illuminance $\left(\mathrm{lm}, \mathrm{m}^{-2}\right)$ of the original FL lamps increases to more than $50 \%$. The illuminance $\left(\mathrm{lm}, \mathrm{m}^{-2}\right)$ significantly increases with the Ar gas pressures. It should be note that the $\mathrm{Hg}$ atoms in the gap absorb the UV lights from the positive column before reaching to the phosphor screen. The results inform us that the decrease in the depth of the gap is an urgent subject for the increase of the illuminance $\left(\mathrm{lm} \mathrm{m}^{-2}\right)$ from the phosphor screen in the FL lamps.

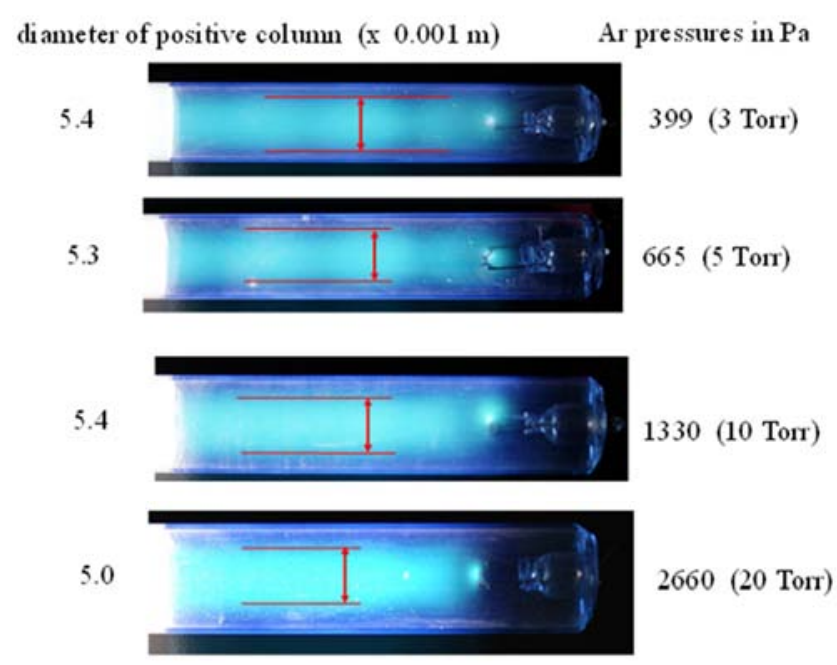

Figure 12. Diameters of positive column in FL lamps in $9.5 \times 10^{-3} \mathrm{~m}(\mathrm{~T}-3)$ as change in Ar gas pressures.

Figure 12 shows the diameter of the positive column in the FL lamps in the diameter $9.5 \times 10^{-3} \mathrm{~m}$ (T-3) with the different Ar gas pressures from $399 \mathrm{~Pa}$ to $2660 \mathrm{~Pa}$. The diameter of the positive column does not change with the Ar gas pressures. We have found that the generation of the gaps relates with the electric charges on the phosphor particles in the screens [14].

\subsection{Determination of Diameters of Positive Column in Lighted FL Lams by the Arrangement of Phosphor Particles}

We have the experiments whether the electric conductivity of the phosphor screen determines in the depths of the gap in the lighted FL tube or not. We have the phosphor screen on a glass plate that is $0.02 \mathrm{~m}$ width and $0.1 \mathrm{~m}$ long. The phosphor screen in a thin layer (less than $3 \mathrm{mg} \mathrm{cm}^{-2}$ ) prepares on the glass plate by the sedimentation in the deionized water without binder. After the dry of the phosphor screen at $110^{\circ} \mathrm{C}$, the phosphor screen is covered with a thin plastic film. Then, the electrically conductive indium-tin oxide (ITO) film coats on the phosphor screens. After the formation of the ITO film on the phosphor screens, the thin plastic layer bakes out from the phosphor screen. The produced phosphor screens set in a small vacuum chamber. The Ar gas pressure in the vacuum chamber is $10^{2:} \mathrm{Pa}$ (=7 Torr). The cathode is made by the sharp needle metal that is covered with the thin frit glass layer less than $1 \times 10^{-4} \mathrm{~m}$ thickness. As the $3 \mathrm{kV}$ DC voltage applies between the needle cathode and plate anode, the needle cathode in the Ar gas space is covered with the volume of the glow light in $3 \times 10^{-3} \mathrm{~m}$ diameter, The glow light is the electron source (cathode) and the plate metal electrode (anode) collects arrived electrons from the Ar gas.
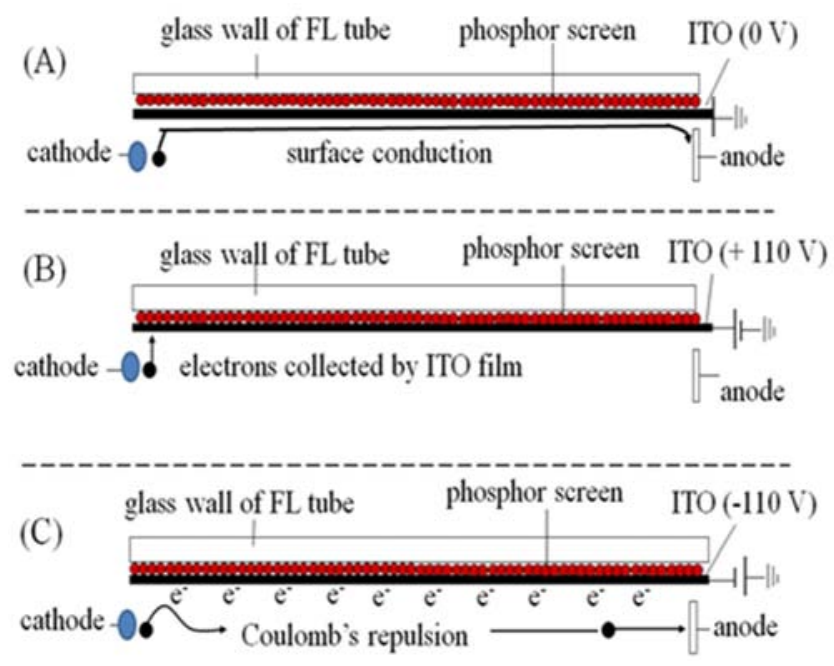

Figure 13. Experimental configurations of electric potentials on phosphor screens which have layers of optically transparent and electric conductive layer of indium-tin-oxide (ITO) films.

Figure 13 shows the experimental configurations. We have respectively applied the DC voltages to the ITO film; e.g., grand (A), $+100 \mathrm{~V}(\mathrm{~B})$, and $-300 \mathrm{~V}(\mathrm{C})$. In the vacuum device, the electrons move from cathode to anode. When the ITO film has the grand that has no electric charge, the electrons from the cathode have the surface conduction on the ITO film, as shown in Figure 13(A). When the ITO film has the positive potential $(\mathrm{DC}=+200 \mathrm{~V})$, the ITO film corrects all the electrons from the cathode, Figure 13 (B). As the ITO film has a negative potential $(\mathrm{DV}=-100 \mathrm{~V})$, Figure $13(\mathrm{C})$, the electrons from the cathode never reach on the ITO film. The negative electric field from the ITO film repulses all approaching electrons to the Ar gas space. The commercial phosphor particles have the SBE negative charges (-2000 V) [14]. From the results in Figure 13, it can say that the repulsed electrons from the SBE move on in the Ar gas space where the electric field in $F_{\text {vect }} \geq F_{\text {phos }}$. Where $F_{\text {vect }}$ is electric filed formed by the cathode and anode, and $\mathrm{F}_{\text {phos }}$ is the vertical electric field from the phosphor particles in the screen.

It is now clear that the phosphor screens of the commercial 
HCFL lamps have produced with the PL phosphor particles. Consequently, the commercial HCFL lamps always have the deep gap in $4 \times 10^{-3} \mathrm{~m}$. So far as the phosphor screen is made with the low voltage CL phosphor particles, the electrons from the cathode move on the surface conduction on the CL phosphor screen in the FL lamps. The results give us the complicated mechanisms of the moving electrons in the lighted FL lamps. The complications give us an idea of the arrangement of the PL phosphor particles and low voltage CL phosphor particles for the generation of the shallow gap less than $3 \times 10^{-4} \mathrm{~m}$.
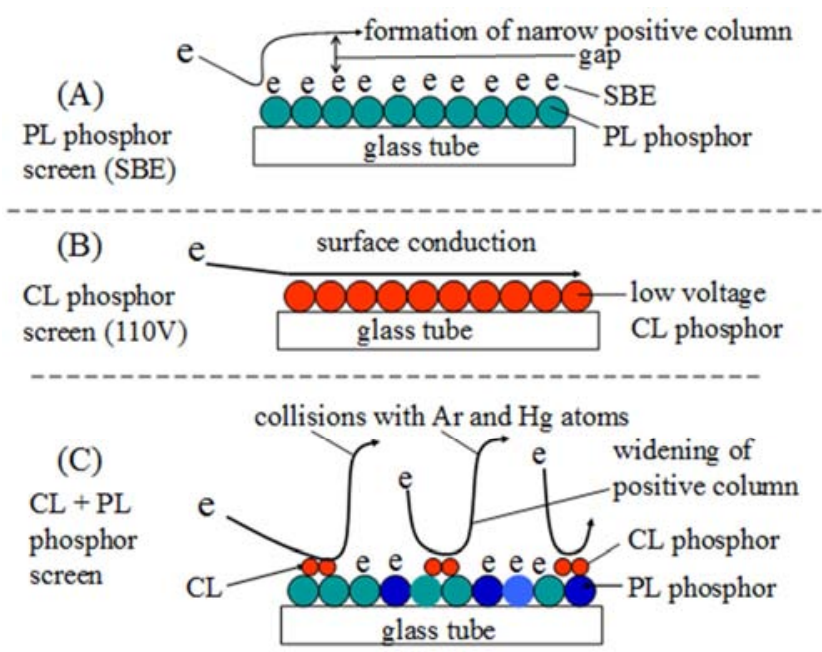

Figure 14. Traces of moving electrons on PL phosphor particles and low voltage CL phosphor particles (red).

We have the study on the traces of the moving electrons on the individual phosphor particles in the screens that have the different $\mathrm{V}_{\text {th }}$ in the VD curves of CL [14]. We take at first the commercial green phosphor particles that the surfaces are heavily contaminated with the electric insulator that gives $V_{\text {th }}$ $=2000 \mathrm{~V}$. Figure 14 (A) illustrates the repulsed electron from the green phosphor screen, giving rise to the deep gap in $4 \mathrm{x}$ $10^{-3} \mathrm{~m}$. The similar results obtain with the blue phosphor screen. As the phosphor screen is made with the low voltage $\mathrm{CL}$ red phosphor particles, the electrons take the surface conduction, Figure 14 (B), without the light in the Ar gas space. The results lead us to the next experiments.

When the low CL voltage phosphor particles arrange side by side on the top layer of the PL phosphor screen, the moving electrons may reach on the surface of the low voltage phosphor particles. The electrons on the low CL phosphor particles are accelerated by the $\mathrm{F}_{\text {vet }}$. The accelerated electrons are strongly repulsed by the electric field of the SBE on the PL phosphor particles. The repulsed electrons in the positive column may have a chance to reach on the surface of the low voltage CL phosphor particles. The moving electrons in the longitudinal direction periodically reach on the surface of the low CL phosphor particles, like as Figure 14 (C). The periodical irregularity of the light intensities on the phosphor screen is beyond of the resolution of the naked eyes. The practical reduction of the depths of the gap may be determined by the measurements of the build-up curves.
Figure 15 shows the build-up curves with the parameters of the ratios of the $\left(\mathrm{V}_{\text {phos }} \mathrm{x} \mathrm{V}_{\mathrm{Ar}}{ }^{-1}\right)=0.8$ and 0.5 , respectively. The illuminance is arbitrary scale. The build-up curve of the improved FL lamp by the $\left(\mathrm{V}_{\text {posi }} \times \mathrm{V}_{\mathrm{Ar}}^{-1}=0.8\right)$ rapidly reaches to the saturation level, indicating the shallow depth of the gap $\left(3 \times 10^{-4} \mathrm{~m}\right)$. The commercial $40 \mathrm{~W}-\mathrm{HCFL}$ tube is $\left(\mathrm{V}_{\text {posi }} \times \mathrm{V}_{\mathrm{Ar}}^{-1}\right.$ $=0.5$ ) with the depth of $4 \times 10^{-3} \mathrm{~m}$. The build-up curves do not change with the Ar gas pressures from $1 \times 10^{2} \mathrm{~Pa}$ (=5Torr) to 7 x $10^{3} \mathrm{~Pa}$ (= 50 Torr).

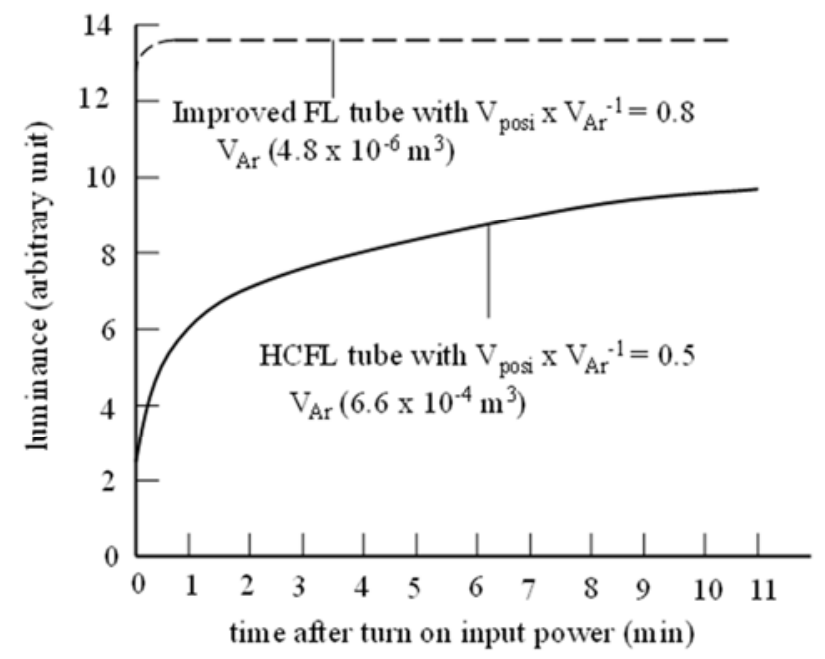

Figure 15. Build up curves of improved phosphor screen in FL tube and commercial HCFL tube.

By the use of the improved FL lamps, we have studied the optimal operation temperatures of the coil-EEFL lamps. The coil-EEFL lamps should be set in the vacuum sealed container for the avoidance of the cooling of the outer glass wall by the air convection at the room temperature $\left(22^{\circ} \mathrm{C}\right)$. The illuminance $\left(\mathrm{lm}, \mathrm{m}^{-2}\right)$ certainly increases with the temperatures of the Ar gas pressures up to $10^{4} \mathrm{~Pa}$ (70 Torr). Then it can say that the established optimum temperature at $40^{\circ} \mathrm{C}$ of the commercial HCFL lamps is controlled by the deep depths $\left(4 \times 10^{-3} \mathrm{~m}\right)$ of the gap between the positive column and phosphor screen.

The phosphor screens of the 40W-HCFL lamps are made by the arrangement of the low voltage CL phosphor particles and the PL phosphor particles, as shown in Figure 14 (C). The $40 \mathrm{~W}-\mathrm{HCFL}$ lamp may have the depth of the gap $\left(3 \times 10^{-4} \mathrm{~m}\right)$. The improved 40W-HCFL lamp with the Ar gas pressure at $931 \mathrm{~Pa}$ (7 Torr) may illuminate the furniture in the $2 \mathrm{~m}^{2}$ room with the illuminance of $300 \mathrm{~lm} \mathrm{~m} \mathrm{~m}^{-2}$. Using the same $40 \mathrm{~W}-\mathrm{HCFL}$ lamp, we may increase the temperatures of the $\mathrm{Ar}$ gas at $60^{\circ} \mathrm{C}$. The HCFL lamps at $60^{\circ} \mathrm{C}$ may have the illuminance $\left(1200 \mathrm{~lm}, \mathrm{~m}^{-2}\right)$ that is 4 times of the illuminance $\left(300 \mathrm{~lm}, \mathrm{~m}^{2}\right)$ with the gap $\left(4 \times 10^{-3} \mathrm{~m}\right)$. However, the HCFL lamps are operated with the $\mathrm{AC}$ driving circuit, so that the $\mathrm{W}_{\text {act }}$ also increases with the Ar gas pressures. Furthermore, the operation life of the $40 \mathrm{~W}-\mathrm{HCFL}$ lamps is around $10^{4}$ hours. The HCFL lamps may less contribute to the Green Energy Project of UN. Only developed coil-EEFL lamps may contribute to the Green Energy Project of UN. 


\section{Conclusion}

We have found that the commercial FL lamps for more than 80 years are designed with the erroneous concepts. We have revised all of them. The Ar atoms in the FL lamps do not combine each other with the electron shell of Ar atoms. The individual Ar atoms float in the vacuum with the separation distance more than $10^{-6} \mathrm{~m}$. The wide vacuum between $\mathrm{Ar}$ atoms provides the superconductive vacuum for the moving electrons in the Ar gas space. Naturally the moving electrons in the Ar gas space do not have the electric resistance R. The moving electrons in the superconductive vacuum have the astronomical quantum efficiency $\left\{\eta_{\mathrm{q}}=3 \times 10^{14}\right.$ visible photons, $\left.\left(\mathrm{m}^{3}, \mathrm{~s}\right)^{-1}\right\}$. The electric current of the FL lamps is $3 \mathrm{x}$ $10^{-4}$ A that contains $2 \times 10^{15}$ electrons per second. Therefore, the FL lamp emits $6 \times 10^{29}$ visible photons $\left(\mathrm{m}^{3}, \mathrm{~s}\right)^{-1}$. The illuminance of the FL lamps holds the unrivaled advantage over other incandescent lamps.

We have found the coexistence of two disparate electric circuits in the operation of the FL lamps. They are the external driving circuit and internal DC electric circuit. There is no electron flow between two disparate electric circuits. The cathode and anode of the internal DC electric circuit are formed by the volume of the glow lights on the polarized phosphor particles under the DC electric field from the electrodes of the external driving circuit. So far as the FL lamps are operated with the DC driving circuit, the electric power consumption of the external driving circuit is zero. Then, we have developed the coil-EEFL lamps as the prototype. The optimization for the mass production of the coil-EEFL lamps remains as a future study by someone else.

In the optimization process of the FL lamps, a very hard problem exists in the lighted FL lamps. The moving electrons in the Ar gas space are seriously influenced by the electric charges on the phosphor particles in the screen. The problem generates the deep gap between positive column and phosphor screen. The commercial HCFL lamps have the deep gap at $4 \mathrm{x}$ $10^{-3} \mathrm{~m}$. By the arrangement of the low voltage CL phosphor particles and PL phosphor particle side by side on the top layer of the phosphor screen, the depth of the gap decrease to be $3 \mathrm{x}$ $10^{-4} \mathrm{~m}$. There is an appropriate diameter of the coil-EEFL lamps that is around $1 \times 10^{-2} \mathrm{~m}(\mathrm{~T}-3)$.

The lighting panels at any sizes with the high illuminance can be made by the arrangement of the plural coil-EEFL lamps in the parallel connections, which are operated with one external DC power supply with $\mathrm{W}_{\mathrm{DC}}=0$. The developed coil-EEFL lamps in the vacuum-sealed container can be operated with the combination of the solar cells and electric battery, without the ordinary networks of the electric power distribution. The coil-EEFL lamps surely contribute to the Paris Agreement and COP of UN projects.

\section{References}

[1] Lyuji Ozawa, [Coil-EEFL tube as supreme incandescent light source with zero electric power consumption, astronomical quantum efficiency, and long life], Global Journal of Science Frontier Research, 15, Issue 8 Version 1.0, pp 16-50, 2015.

[2] Lyuji Ozawa and TianYakui, [Restriction of solid lighting sources in practical use], J. China Illum. Engs. Soc., 6, pp 57-64, 2011.

[3] F. Meyer, US Pat. 2,182,732 (1928).

[4] Lyuji Ozawa, [Unrivaled incandescent lamp for green energy project], World Journal of Applied physics, 1 (1), pp 1-15, 2016; online publication, $\mathrm{http} / \mathrm{www}$. sciencepublicationgroup.com/j/fap.

[5] Phosphor Handbook, second edition, by William Yen, ISBN: 0849335647, CRC Press, Taylor \& Francis Group, Boca Raton, London, New York, (1998).

[6] Discharge Handbook, Japanese Electric Society, (1973).

[7] J. F. Waymouth, [Electron discharge lamp], MIT Press (1971).

[8] Lyuji Ozawa and Yakui Tian, [A new 4G electron source for fluorescent lamp tubes], J. China Ill. Soc., 7, pp58-65, 2012.

[9] Lyuji Ozawa and Yakui Tian [New electron source and electron collection source in FL tube], Korean J. Inf. Display, 12, pp 69-74, 2011.

[10] Lyuji Ozawa, [Illuminance of FL tubes controlled by depth of gap between positive column and phosphor screen], Science Research, 3 (3), pp93-104, (2015), online publication, $\mathrm{http} / / \mathrm{www}$. sciencepublicationgroup.com $/ \mathrm{j} / \mathrm{sr}$.

[11] Lyuji Ozawa and Yakui Tian, [A breakthrough in the study on FL tubes], J. China Ill. Soc., 8, pp86-94, 2013.

[12] Lyuji Ozawa and Yakui Tian, [Coexistence of disparities of external AC driving circuit and internal DC electric circuit in operation in FL tubes], J. China Ill. Soc., 6, pp19-30, 2011.

[13] Lyuji Ozawa, [Ideal distribution of polycrystalline phosphor particles for application to phosphor screens in CRT], International Journal of Materials Science and Applications, 6(1): pp 6-17, 2017, online publication, http//www. sciencepublicationgroup.com/j/ijmsa.

[14] Lyuji Ozawa, [Special arrangement of phosphor particles in screen for optimization of illuminance $\left(1 \mathrm{~m}, \mathrm{~m}^{-2}\right)$ of FL tubes, Science Research, 3 (6), pp 261-272, (2015), online publication, $\mathrm{http} / / \mathrm{www}$. sciencepublicationgroup.com/j/sr. 